\title{
Bone mineral density in healthy Kuwaiti women
}

\author{
S. Mahussain • H. Badr $\cdot$ K. Al-Zaabi • \\ M. Mohammad $\cdot$ N. Alnafisi
}

Received: 4 June 2006 / Accepted: 2 October 2006 / Published online: 16 December 2006

(C) International Osteoporosis Foundation and National Osteoporosis Foundation 2006

\begin{abstract}
Objective This study aimed to measure bone mineral density (BMD) of the lumber spine and femur regions in healthy adult Kuwaiti women, and to evaluate the influence of body size on BMD results.

Methods Bone mass measurement was performed by dualenergy X-ray absorptiometry at the lumbar spine (L2-L4) and femur (four regions) of healthy ambulatory Kuwaiti females aged between 20 and 80 years. Body size measurements and a detailed questionnaire on past medical and gynecologic history, as well as lifestyle factors, were administered to all subjects. After excluding those with apparent or suggested abnormalities affecting bone mass, only 805 women from 4,887 were included and served as the target subjects.

Results The spine BMD values for Kuwaiti women up to 69 years old were lower than their US counterparts; the peak value was established in the fifth decade. Femur neck BMD was relatively stable up to menopause. Spine osteoporosis was prevalent among $10 \%$ of the subjects, compared with $4 \%$ in the femoral neck. Regression analysis revealed that each kilogram of body weight has a change of $0.3 \%$ in
\end{abstract}

S. Mahussain $\cdot$ K. Al-Zaabi $\cdot$ M. Mohammad $\cdot$ N. Alnafisi

Department of Nuclear Medicine,

Ministry of Health, Amiri Hospital,

Kuwait

H. $\operatorname{Badr}(\bowtie)$

Department of Community Medicine and Behavioral Sciences, Faculty of Medicine, Kuwait University,

Kuwait

e-mail: hanan29@yahoo.com

H. Badr

Department of Family Health,

High Institute of Public Health, Alexandria University,

Alexandria, Egypt premenopausal women and $0.5-0.6 \%$ in the older group. In multiple regressions that included the three factors (height, weight and age), the effect of age superseded that of weight in the older group of women, where there was a detrimental annual effect on spine and femur (neck and total hip) BMD by $0.9 \%$, while each kilogram of body weight had a constructive effect by 0.4 and $0.3 \%$. In the premenopausal women, the positive effect of $1 \mathrm{~kg}$ of body weight was equivalent to about 1 year of aging in the trochanter region and half a year in the total hip region.

Conclusion The BMD value of healthy Kuwaiti women tend to be lower than the US reference at the lumber spine in all age groups but showed higher values for femur neck only in the age group of late $30 \mathrm{~s}$ through 60 years. Weight has a stronger effect on BMD than does the height. The prevalence of osteoporosis in the lumber spine was more than double that in the femur neck in postmenopausal women.

Keywords Bone mineral density · DXA $\cdot$ Kuwait . Osteoporosis

\section{Introduction}

Osteoporosis is a disorder characterized by compromised bone strength predisposing to an increased risk of fractures. Bone strength reflects the integration of two main features: bone density and bone quality [1].

It is in fact a public health problem affecting one third of women in the USA and it is of increasing social and economic importance as the size of the aging population continues to grow [2].

According to the World Health Organization, osteoporosis is defined as a bone mass density $2.5 \mathrm{SD}$ (T-score $\leq-2.5$ ) or more below peak bone mass (PBM) as measured by dual 
energy X-ray absorptiometry (DXA). PBM itself is defined as the average maximum bone mass achieved by young healthy sex- and race-matched adults. On the other hand, osteopenia is defined as a BMD between 1.0 and 2.5 SD below PBM (T-score between -1 and -2.5) [3].

There has been rapid development of DXA for measuring bone mineral density (BMD in $\mathrm{g} / \mathrm{cm}^{2}$ ) in the axial skeleton for diagnosing osteopenia and osteoporosis, for ascertaining fracture risk and for monitoring treatment [4]. These systems contain sets of BMD reference data for different populations, as appropriate reference values are critical for clinical evaluation of normality and manufacturers usually provide these values in their densitometers [5].

However, it is well known that there are significant differences in BMD between age groups of different sexes and geographical areas [6-13]. For example, BMD values in black women exceed those in white women; values in white women exceed those in Asian women; values in white women in the United States/Northern Europe are greater than those in Lebanese and Saudi Arabian women $[6,8,10,12]$. Accordingly, bone mineral density measurement should be related to normal values specific for the patient's race and gender. Several studies were conducted in the local region to measure BMD in different populations, such as Lebanon [2, 10], Saudi Arabia [6, 8] and a preliminary study in Kuwait [12]. Thus, the objectives of this study were to measure BMD at the lumbar spine and femur in healthy adult Kuwaiti women, to assess the prevalence of osteoporosis and to evaluate the influence of body size especially weight on BMD results.

\section{Materials and methods}

\section{Sample selection}

All measurements were made on ambulatory Kuwaiti women. Eight hundred and five healthy subjects, aged 20-79 years, were selected from 4,887 Kuwaiti females referred for bone mass density measurements in the department of Nuclear Medicine at Al.Amiri Hospital in the period from July 2001 till October 2005.

\section{Exclusive criteria}

Women with extremities of weight who weighted less than the fifth percentile $(45 \mathrm{~kg})$ or more than the 95 percentile $(85 \mathrm{~kg})$ were excluded from the study. Any woman with a current or past medical history that might influence the BMD measurements was also excluded. These cases were: prolonged secondary amenorrhea; connective tissue disease, such as rheumatoid arthritis; history of endocrine or metabolic disorders, such as thyrotoxicosis, hypothyroidism or diabetes mellitus; major chronic diseases (intestinal, liver, kidney, heart) or cancer; history of radiation therapy or chemotherapy; history of oopherectomy or hysterectomy before menopause; intake of medications that affects bone metabolism, such as steroids, hormone replacement therapy, biphosphonates, selective estrogen receptor modulator (SERM), thyroxin, anticoagulants, calcium or vitamin D. Accordingly, any adult Kuwaiti female who had no past medical history of any problem listed above was legible for the study after getting her verbal consent.

Anthropometric measurements, lifestyle and reproduction factors

A face-to-face interview was conducted with each selected legible female. The interview questionnaire included sociodemographic information (e.g., age, age of menopause). Questions related to their smoking status, caffeine consumption, dairy products consumption and practicing exercise were included. Reproductive history covered parity and lactation period. Subjects were weighed on an electrical scale to the nearest half kilogram. Height was measured using a stadiometer to the nearest half centimeter. Body mass index (BMI) was calculated as weight $(\mathrm{kg}) /$ height $(\mathrm{m})^{2}$.

\section{Bone density measurements}

BMD of the lumbar spine (L2-L4) and bilateral femur (neck, Ward's triangle, trochanter, and total hip) in posteroanterior projection was measured using one DXA machine (Lunar Prodigy densitometer) at the Nuclear Medicine Department in Al.Amiri Hospital. The Middle East reference database provided by the manufacturer was being used for calculating T-scores for establishing the prevalence of osteopenia and osteoporosis.

\section{Quality assurance of densitometer}

Machine calibration was done daily. Spine phantoms were measured daily as recommended by the DXA machine manufacturer and the mean coefficient of variation $\{\mathrm{CV} \%$; expressed as [standard deviation (SD)/mean] $\times 100$ of all daily replicate measurements of the spine phantom for duration of the study was less than $1 \%$. The in vivo precision error (CV \%) were $1.5 \%$ for the lumber spine, $2 \%$ for the femoral neck, and $1.8 \%$ for the total hip.

\section{Data analysis}

The collected data were entered and analyzed using the Statistical Package for Social Sciences (SPSS) version 13. Mean, SD, simple and multiple linear regression analysis were performed to detect the association between the 
Table 1 Height $(\mathrm{cm})$, weight $(\mathrm{kg})$, and BMI $\left(\mathrm{kg} / \mathrm{m}^{2}\right)$ of normal Kuwaiti women

\begin{tabular}{|c|c|c|c|c|c|c|c|}
\hline \multirow[t]{2}{*}{ Age in years } & \multirow[t]{2}{*}{$n$} & \multicolumn{2}{|l|}{ Height } & \multicolumn{2}{|c|}{ Weight } & \multicolumn{2}{|l|}{ BMI } \\
\hline & & Mean & SD & Mean & SD & Mean & SD \\
\hline $20-29$ & 15 & 159.6 & 5.7 & 68.0 & 7.9 & 26.8 & 3.3 \\
\hline $30-39$ & 38 & 157.5 & 5.9 & 67.1 & 9.3 & 27.1 & 3.9 \\
\hline $40-49$ & 279 & 156.3 & 6.1 & 70.1 & 9.2 & 28.7 & 3.7 \\
\hline $50-59$ & 298 & 154.6 & 5.7 & 70.8 & 8.3 & 29.7 & 3.9 \\
\hline $60-69$ & 125 & 151.1 & 7.5 & 70.4 & 9.3 & 31.0 & 4.6 \\
\hline $70-79$ & 50 & 149.8 & 6.8 & 66.5 & 11.4 & 29.7 & 5.1 \\
\hline $20-79$ & 805 & 154.6 & 6.6 & 70.0 & 9.1 & 29.4 & 4.1 \\
\hline
\end{tabular}

different variables. The level of significance was $P<0.05$ and confidence interval (CI) was $95 \%$.

\section{Results}

The study was conducted among 805 healthy Kuwaiti women selected from an original 4,887 Kuwaiti females referred for bone mass density measurements after applying the exclusion criteria listed in the Materials and methods section. Only $1.1 \%$ of them were currently smokers; more than one third of them $(35.3 \%)$ consumed about 2 cups of caffeine/day. Less than one half of them (43\%) consumed around 1.5 cups of dairy products/day, but only $15 \%$ practiced exercise for about $1.5 \mathrm{~h} /$ week. Parity was experienced by $85 \%$ of the subjects with an average of four times; and $35.8 \%$ of them experienced lactation for a mean of 8 months.

Table 1 shows the heights, weights and BMI by decade. The average height and weight were $155 \mathrm{~cm} \pm 7$ and $70 \mathrm{~kg} \pm 9$, respectively. The mean BMI was $29 \mathrm{~kg} / \mathrm{m}^{2} \pm 4$, where about $40 \%$ of the women were overweight (BMI 25-29.9) and $44.3 \%$ were obese $(B M I \geq 30)$. The mean spine and femoral region (neck and total hip) BMD in different decades are shown in Table 2.
Spine BMD showed a very slight increase to reach its highest value in the fifth decade. The femur neck BMD was relatively stable from 20 to 49 years. BMD values in the present study were comparable with previous study data in the USA [14] (Figs. 1, 2). The spine BMD values for the Kuwaiti sample were significantly lower than the American average in almost all age groups but for the age group 50 59 years. Similarly, the data for the femur neck BMD of young women (20-29 years) followed the spine BMD pattern, but the difference from the corresponding US females was insignificant. In the ages from late 30 s through almost 60 years, the BMD in the Kuwaiti females showed significantly higher values than their USA counterparts, except in the age group from 60 to 69 years where the difference was insignificant, and returned back significantly to the former picture after age 60 .

The prevalence of osteopenia and osteoporosis in the women aged from 50 to 79 years was demonstrated in Table 3. The table indicates that spine and femur neck osteopenia showed a very close distribution ( $27 \%$ and $25 \%$, respectively), while spine osteoporosis was more than double the prevalence in the femur neck region $(10 \%$ and $4 \%$, respectively).

The influence of height and weight on BMD was investigated by regression analysis, as illustrated in Tables 4 and 5. The positive effect of height was more apparent in the postmenopausal women than in the premenopausal group; each centimeter of height had a significant change in BMD by $0.2-0.3 \%$ (spine and femur neck only, respectively) in premenopausal women compared with $0.4-0.5 \%$ (spine, femur neck and Ward's regions) in older women. The effect of weight was stronger than height, where each kilogram of body weight had a change of $0.3 \%$ in premenopausal women and $0.5-0.6 \%$ in the older group. In the multiple regressions that included height and weight, the latter had about 3- to 5-times greater effect on BMD than the former. Multiple regressions of height, weight and age for premenopausal women (20-49 years) and postmen-

Table 2 Age-specific values of bone mineral density in posteroanterior (PA) spine and femur (neck and total hip)

\begin{tabular}{|c|c|c|c|c|c|c|c|c|c|c|}
\hline \multirow[t]{3}{*}{ Age (years) } & \multirow[t]{3}{*}{$n$} & \multicolumn{3}{|c|}{ PA spine (L2-L4) } & \multicolumn{6}{|l|}{ Femur } \\
\hline & & \multirow[t]{2}{*}{ Mean } & \multirow[t]{2}{*}{ SD } & \multirow[t]{2}{*}{$95 \% \mathrm{CI}$} & \multicolumn{3}{|l|}{ Neck } & \multicolumn{3}{|c|}{ Total hip } \\
\hline & & & & & Mean & $\mathrm{SD}$ & $95 \% \mathrm{CI}$ & Mean & SD & $95 \% \mathrm{CI}$ \\
\hline 20-29 & 15 & 1.108 & 0.15 & $1.027-1.189$ & 0.964 & 0.11 & $0.906-1.022$ & 0.988 & 0.13 & $0.916-1.060$ \\
\hline $30-39$ & 38 & 1.138 & 0.12 & $1.099-1.177$ & 0.945 & 0.09 & $0.920-0.978$ & 0.974 & 0.08 & $0.947-1.001$ \\
\hline $40-49$ & 279 & 1.148 & 0.15 & $1.130-1.165$ & 0.959 & 0.11 & $0.945-0.972$ & 1.013 & 0.12 & $0.999-1.027$ \\
\hline $50-59$ & 298 & 1.096 & 0.16 & $1.078-1.114$ & 0.931 & 0.13 & $0.916-0.946$ & 1.005 & 0.14 & $0.989-1.021$ \\
\hline $60-69$ & 125 & 0.964 & 0.16 & $0.934-0.993$ & 0.811 & 0.11 & $0.791-0.831$ & 0.893 & 0.12 & $0.871-0.915$ \\
\hline $70-79$ & 50 & 0.915 & 0.16 & $0.868-0.961$ & 0.717 & 0.10 & $0.689-0.746$ & 0.802 & 0.13 & $0.766-0.839$ \\
\hline $20-79$ & 805 & 1.085 & 0.17 & $1.072-1.096$ & 0.910 & 0.14 & $0.900-0.920$ & 0.976 & 0.14 & $0.966-0.986$ \\
\hline
\end{tabular}




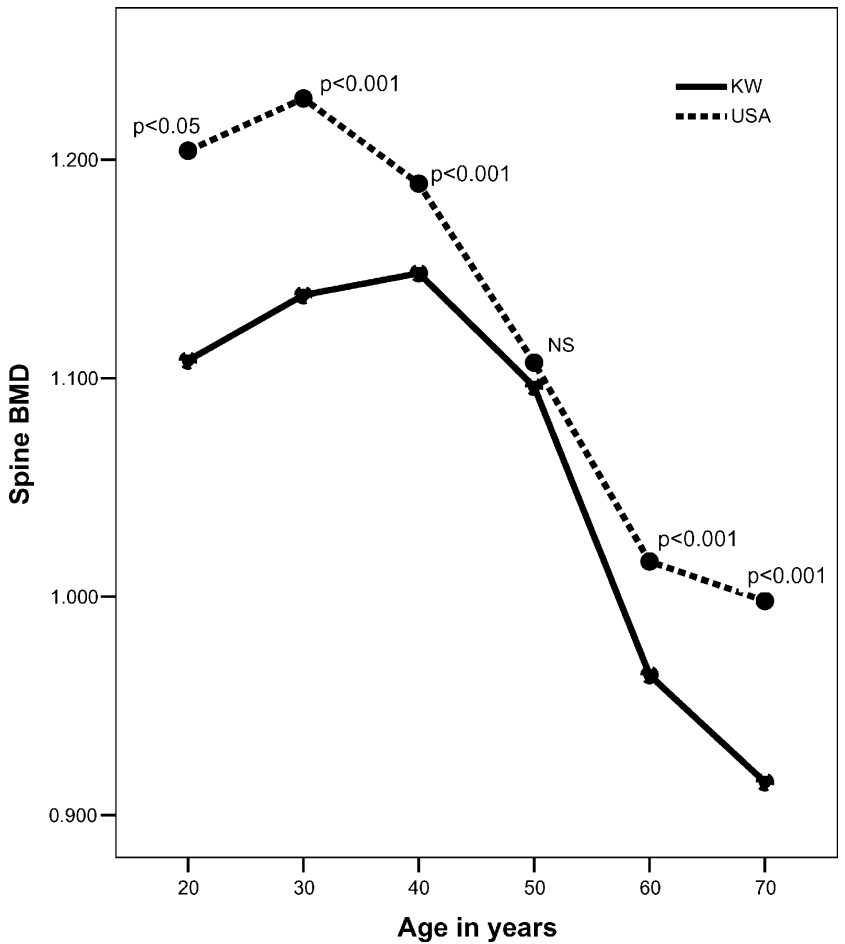

Fig. 1 Spine BMD according to age in healthy adult Kuwaiti women and USA women (NS not significant)

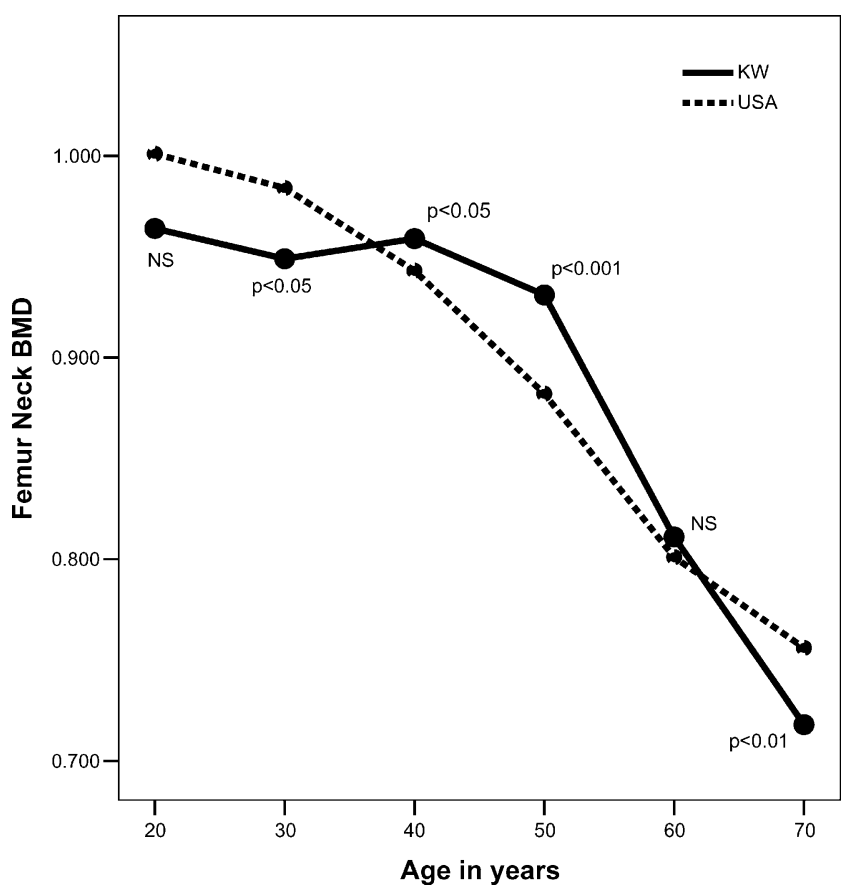

Fig. 2 Femur neck BMD according to age in healthy adult Kuwaiti women and USA women ( $N S$ not significant)
Table 3 Prevalence of osteoporosis (T-score of $<-2.5$ SD) and osteopenia (T-score $>-2.5 \mathrm{SD}$ and $<-1 \mathrm{SD}$ ) in Kuwaiti women $50-79$ years $(n=473)$

\begin{tabular}{llllll}
\hline \multirow{2}{*}{ Age } & \multicolumn{2}{l}{ Spine } & & & Femur neck \\
\cline { 2 - 3 } \cline { 5 - 6 } \cline { 5 - 6 } & $\begin{array}{l}\text { Osteopenia } \\
n(\%)\end{array}$ & $\begin{array}{l}\text { Osteoporosis } \\
n(\%)\end{array}$ & & $\begin{array}{l}\text { Osteopenia } \\
n(\%)\end{array}$ & $\begin{array}{l}\text { Osteoporosis } \\
n(\%)\end{array}$ \\
\hline $50-59$ & $65(13.7)$ & $9(1.9)$ & & $44(9.3)$ & $0(0.0)$ \\
$60-69$ & $44(9.3)$ & $22(4.7)$ & & $50(10.6)$ & $8(1.7)$ \\
$70-79$ & $18(3.8)$ & $16(3.4)$ & & $24(5.1)$ & $11(2.3)$ \\
$50-79$ & $127(26.8)$ & $47(9.9)$ & & $118(24.9)$ & $19(4.0)$
\end{tabular}

opausal women (50-79 years), height did not demonstrate any significant influence on the BMD of any region.

Age was a significant constructive factor only for femur trochanter and total hip regions in the premenopausal group, where BMD increased annually by 0.4 and $0.3 \%$, respectively. However, it demonstrated a highly significant detrimental effect in all bone regions in the postmenopausal women. In this latter group, BMD decreased an average of $1 \%$ annually, except for the trochanter where the rate was $0.7 \%$. In the multiple regressions that included the three factors (height, weight and age), the effect of age superseded that of weight in the older group of women, where there was a detrimental annual effect on spine and femur (neck and total hip) BMD by $0.9 \%$, while each kilogram of body weight had a constructive effect by 0.4 and $0.3 \%$. In the premenopausal women, the effect of $1 \mathrm{~kg}$ of body weight was equivalent to about 1 year of aging in the trochanter region and half a year in the total hip region.

\section{Discussion}

This report outlined BMD values from a group of ambulatory healthy Kuwaiti females with exclusion of extreme body weights. Subjects were also excluded on the basis of medical conditions or medication known to affect bone mass density.

The present study revealed that PBM was achieved in the fifth decade for the spine and total hip, and in the third decade for the femur neck. This was similar to the Saudi results on healthy Saudi females [6, 8]. Other studies showed PBM in females at the third decade of life irrespective to bone regions [12, 14], and at the fourth decade [6]. These differences in PBM density at maturity may be accounted for by differences in race and lifestyle. Asian women also have lighter bones which were partially attributed to their low body weight [15]. In addition, the age at which PBM is attained is suggested to be different among skeletal sites as well, occurring earlier in the femoral region than in the spine region [16].

An important finding was that the mean value for spine BMD in all age groups was lower than those reported from 
Table 4 Regression of BMD for spine and femur regions $(n=332)$ on height $(H T)$, weight $(W T)$, and age in Kuwaiti women $20-49$ years

\begin{tabular}{|c|c|c|c|}
\hline \multicolumn{2}{|l|}{ Region } & \multirow{2}{*}{$\begin{array}{l}r \\
0.12\end{array}$} & \multirow{2}{*}{$\begin{array}{l}P \\
0.01\end{array}$} \\
\hline Spine (L2-L4) & $0.687+0.003 \mathrm{HT}$ & & \\
\hline Femur (neck) & $0.495+0.003 \mathrm{HT}$ & 0.16 & 0.002 \\
\hline Femur (Ward's $\Delta$ ) & $0.557+0.002 \mathrm{HT}$ & 0.08 & NS \\
\hline Femur (trochanter) & $0.828+0.000 \mathrm{HT}$ & -0.01 & NS \\
\hline Femur (total) & $0.898+0.001 \mathrm{HT}$ & 0.04 & NS \\
\hline Spine (L2-L4) & $0.960+0.003 \mathrm{WT}$ & 0.17 & 0.001 \\
\hline Femur (neck) & $0.733+0.003 \mathrm{WT}$ & 0.27 & $<0.0001$ \\
\hline Femur (Ward's $\Delta$ ) & $0.597+0.003 \mathrm{WT}$ & 0.22 & $<0.0001$ \\
\hline Femur (trochanter) & $0.568+0.003 \mathrm{WT}$ & 0.29 & $<0.0001$ \\
\hline Femur (total) & $0.725+0.004 \mathrm{WT}$ & 0.32 & $<0.0001$ \\
\hline Spine (L2-L4) & $1.059+0.002 \mathrm{Age}$ & 0.08 & NS \\
\hline Femur (neck) & $0.931+0.001$ Age & 0.03 & NS \\
\hline Femur (Ward's $\Delta$ ) & $0.838-0.001$ Age & -0.02 & NS \\
\hline Femur (trochanter) & $0.618+0.004$ Age & 0.22 & $<0.0001$ \\
\hline Femur (total) & $0.892+0.003$ Age & 0.13 & 0.01 \\
\hline Spine (L2-L4) & $0.564+0.002 \mathrm{HT}+0.002 \mathrm{WT}+0.002$ Age & 0.19 & 0.004 \\
\hline Femur (neck) & $0.477+0.002 \mathrm{HT}+0.003 \mathrm{WT}+0.000 \mathrm{Age}$ & 0.28 & $<0.0001$ \\
\hline Femur (Ward's $\Delta$ ) & $0.634+0.005 \mathrm{HT}+0.003 \mathrm{WT}-0.001 \mathrm{Age}$ & 0.22 & 0.001 \\
\hline Femur (trochanter) & $0.609-0.001 \mathrm{HT}+0.003 \mathrm{WT}+0.003 \mathrm{Age}$ & 0.35 & $<0.0001$ \\
\hline Femur (total) & $0.791-0.001 \mathrm{HT}+0.004 \mathrm{WT}+0.002 \mathrm{Age}$ & 0.33 & $<0.0001$ \\
\hline
\end{tabular}

their USA counterparts [14], although the average body weight and BMI of the Kuwaiti women were higher. This could be possibly due to the effect of low vitamin D (25OHD) and how much it might contribute to low bone mass density. Vitamin D insufficiency or deficiency is not an uncommon disease in the Middle East region as reported in countries such as Jordan [17], Lebanon [18] and Kuwait [19]. Although the sunshine is available all year around, the level of serum vitamin D (25-OHD) was found to be low (below 20 pmole/l) in 43 out of 50 (86\%) young healthy veiled Kuwaiti females. This was attributed to the heavy clothing worn and avoidance of exposure to sun [19]. Other contributing factors to low bone density should be also considered such as lack of exercise, inappropriate nutrition (low in calcium and vitamin D), multiparity and lactation.

Another finding demonstrated in Fig. 2 was a peculiar BMD pattern for the femur neck region. The mean BMD values for females from late 30 s to almost 60 years of age

Table 5 Regression of BMD for spine and femur regions $(n=473)$ on height $(H T)$, weight $(W T)$, and age in Kuwaiti women $50-79$ years

\begin{tabular}{|c|c|c|c|}
\hline \multicolumn{2}{|l|}{ Region } & \multirow{2}{*}{$\frac{(r)}{0.17}$} & \multirow{2}{*}{$\frac{(P)}{<0.0001}$} \\
\hline Spine (L2-L4) & $0.359+0.004 \mathrm{HT}$ & & \\
\hline Femur (neck) & $0.160+0.005 \mathrm{HT}$ & 0.21 & $<0.0001$ \\
\hline Femur (Ward's $\Delta$ ) & $0.157+0.004 \mathrm{HT}$ & 0.15 & 0.001 \\
\hline Femur (trochanter) & $0.481+0.002 \mathrm{HT}$ & 0.09 & 0.02 \\
\hline Femur (total) & $0.425+0.003 \mathrm{HT}$ & 0.15 & 0.001 \\
\hline Spine (L2-L4) & $0.617+0.006 \mathrm{WT}$ & 0.31 & $<0.0001$ \\
\hline Femur (neck) & $0.508+0.005 \mathrm{WT}$ & 0.33 & $<0.0001$ \\
\hline Femur (Ward's $\Delta$ ) & $0.366+0.005 \mathrm{WT}$ & 0.27 & $<0.0001$ \\
\hline Femur (trochanter) & $0.426+0.005 \mathrm{WT}$ & 0.33 & $<0.0001$ \\
\hline Femur (total) & $0.529+0.006 \mathrm{WT}$ & 0.36 & $<0.0001$ \\
\hline Spine (L2-L4) & $1.608-0.01$ Age & -0.43 & $<0.0001$ \\
\hline Femur (neck) & $1.464-0.01 \mathrm{Age}$ & -0.55 & $<0.0001$ \\
\hline Femur (Ward's $\Delta$ ) & $1.368-0.011$ Age & -0.55 & $<0.0001$ \\
\hline Femur (trochanter) & $1.160-0.007$ Age & -0.39 & $<0.0001$ \\
\hline Femur (total) & $1.520-0.01 \mathrm{Age}$ & -0.51 & $<0.0001$ \\
\hline Spine (L2-L4) & $1.173+0.000 \mathrm{HT}+0.005 \mathrm{WT}-0.009$ Age & 0.50 & $<0.0001$ \\
\hline Femur (neck) & $1.051+0.001 \mathrm{HT}+0.004 \mathrm{WT}-0.009 \mathrm{Age}$ & 0.60 & $<0.0001$ \\
\hline Femur (Ward's $\Delta$ ) & $1.238-0.001 \mathrm{HT}+0.003 \mathrm{WT}-0.011 \mathrm{Age}$ & 0.56 & $<0.0001$ \\
\hline Femur (trochanter) & $1.023-0.001 \mathrm{HT}+0.004 \mathrm{WT}-0.006 \mathrm{Age}$ & 0.48 & $<0.0001$ \\
\hline Femur (total) & $1.261-0.001 \mathrm{HT}+0.005 \mathrm{WT}-0.009 \mathrm{Age}$ & 0.58 & $<0.0001$ \\
\hline
\end{tabular}


were higher than their USA counterparts, while BMD values for the two extremes of age (20-29 years) and (over 60 years) were lower. Similar findings were reported by Hammoudeh et al. [20], in the spine and total femur in Qatari women when they were compared with Caucasians. Also, there was no diminution of axial BMD values in the 30- to 39-year-old women in either spine or femur neck. This was well demonstrated in longitudinal studies in premenopausal women [21].

Moreover, our findings showed that bone changes were more rapid within the first 10 years post menopause than in subsequent periods particularly for spine BMD, others found it more accelerated within the first 3-5 years after menopause [22, 23]. This might explain the higher prevalence of spine osteoporosis over the femur neck osteoporosis.

As reported by others also, spinal bone loss slowed down by age 60 , but femoral bone loss continued [23]. It is well known that trabecular bone loss proceeds from young adulthood onward, whereas compact bone loss seems not to occur until menopause [24, 25].

The effect of body weight on the BMD changes was very comprehensible in our results. It showed that each change of $1 \mathrm{~kg}$ was associated with a change of $0.3-0.4 \%$ in BMD of the spine and femur in younger women and the weight effect was larger in our sample for women over age 50 years $(0.5-0.6 \%)$. This is in concordance with the findings of earlier studies [26], where they found that body weight profoundly influenced the percentage of abnormality. The earlier studies showed that each change of $1 \mathrm{~kg}$ was associated with a change of $0.3-0.4 \%$ in BMD of the spine or femur neck. Others have shown that postmenopausal bone loss is minimal in over weight women and accelerated in the thinnest women [27].

The study also revealed the positive role of height on BMD changes. In the younger group of women each $1 \mathrm{~cm}$ of height showed a significant change of $0.3 \%$ of BMD in the spine and femur neck only. However the significant effect of height was obvious in BMD of all skeletal regions in older women with a change between $0.2-0.5 \%$.

Of the 473 women in our sample between 50 and 79 years of age, 47 (9.9\%) were below the conventional $-2.5 \mathrm{SD}$ threshold of osteoporosis in the spine and 19 $(4.0 \%)$ in the femur neck using the Middle East reference database provided by the manufacturer. In comparison with a healthy Lebanese population, the mean femur neck BMD values were significantly higher in Kuwaiti females in the age range 30-59 years $(P<0.01,0.0001$ and 0.0001 , respectively), while spine BMD values were also significantly higher among Kuwaiti females in the age group 40-49 years $(P<0.01)$, but the reverse was observed in Lebanese females in the age group 50-59 years $(P<0.0001)$. In addition, the prevalence of spine and femur neck osteoporosis were significantly $(P<0.0001)$ higher in the spine $(11 \%)$ of female Lebanese and lower in the femoral neck $(2 \%)(P=0.5)$ using Lebanese reference data [10]. This could be referred to the higher prevalence of obesity in the Kuwaiti females relative to their Lebanese counterparts. This prevalence also might be changed when using a different reference data base. On the other hand, presence of other uncommon risk factors for osteoporosis that were not included in the study should not be neglected as a limitation of the present study.

\section{Conclusion}

The BMD values of healthy Kuwaiti women have had a propensity to be lower than the US reference at the lumber spine in all age groups, but showed higher values for femur neck only in the age group of late 30 s through 60 years. Weight demonstrated a stronger effect on BMD than did height. The prevalence of osteoporosis in the lumber spine was more than double that in the femur neck in postmenopausal women. These results might differ when using a US database.

The findings suggested that Kuwaiti BMD values might be different from USA values to warrant a separate reference sample with which to compare individuals for the purpose of early detection of osteoporosis and osteopenia.

Acknowledgments The authors thank Mrs. A. Alqattan, a nuclear medicine technologist, for her input in this study.

\section{References}

1. NIH Consensus Developmental Panel (2001) JAMA 285:785795

2. Elhajj G, Baddoura R, Awada H et al (2002) Low peak bone mineral density in healthy Lebanese subjects. Bone 31:520-528

3. Assessment of fracture risk and its applications to screening for postmenopausal osteoporosis. Report of a WHO Study Group. World Health Organ Tech Rep Ser 1994;843:1-129

4. Kroger H, Lunt M, Reeve J et al (1999) Bone density reduction in various measurement sites in men and women with osteoporotic fractures of spine and hip: the European quantification of osteoporosis study. Calcif Tissue Int 64:191-199

5. Simmons A, Simpson DE, O'Doherty MJ et al (1997) The effects of standardization and reference values on patients' classification for spine and femur dual energy X-ray absorptopometry. Osteoporos Int 7:200-206

6. El-Desouki M (1995) Bone mineral density of the spine and femur in the normal Saudi population. Saudi Med J 16:30-35

7. Bhudhikanok GS, Wng MC, Ecket K et al (1996) Differences in bone mineral in young Asian and Caucasian Americans may reflect differences in bone size. J Bone Res 11:1545-1556

8. Ghannam NN, Hammami MM, Bakheet SM et al (1999) Bone mineral density of the spine and femur in healthy Saudi females: relation to vitamin $\mathrm{D}$ status, pregnancy and lactation. Calcif Tissue Int 65:23-28 
9. Bachrach LK, Hastie T, Wang MC et al (1999) Bone mineral acquisition in healthy Asian, Hispanic, Black and Caucasian youth: a longitudinal study. J Clin Endocrinol Metab 84:4702-4712

10. Maalouf G, Salem J, Sandid M et al (2000) Bone mineral density of the Lebanese reference population. Osteoporos Int 11:756-764

11. Deleze' M, Cons-Molina F, Villa AR et al (2000) Geographic differences in bone mineral density of Mexico women. Osteoporos Int 11:562-569

12. Dougherty G, Al-Marzouk N (2001) Bone density measured by dual energy X-ray in healthy Kuwaiti women. Calcif Tissue Int 68:225-229

13. Wu XP, Liao EY, Huang $G$ et al (2003) A comparison study of reference curves of bone mineral density at different skeletal sites in native Chineses, Japanese and American Caucasian women. Calcif Tissue Int 73:122-132

14. Mazess RB, Barden H (1999) Bone density of the spine and femur in adult white females. Calcif Tissue Int 65:91-99

15. Kin K, Kusheda K, Yamazaki K et al (1991) Bone mineral density of the spine in normal Japanese subjects using dual X-ray absorptiometry: effect of obesity and menopausal status. Calcif Tissue Int 49:101-106

16. Iki M, Kagamimori S, Kagawa $Y$ et al (2001) Bone mineral density of the spine, hip and distal forearm in representative samples of the Japanese female population: Japanese populationbased osteoporosis study. Osteoporos Int 12:529-537

17. Mishal AA (2001) Effects of different dress styles on vitamin D levels in healthy young Jordanian women. Osteoporos Int 12:931-935
18. Gannage-Yared MH, Chemali R, Yaacoub N et al (2000) Hypovitaminosis D in asunny country: relation to life style and bone markers. J Bone Miner Res 15:1856-1862

19. El-Sunbaty MR, Abdul-Ghaffar NU (1996) Vitamin D deficiency in veiled Kuwaiti women. Europ J Clinc Nutrition 50:315-318

20. Hammoudeh M, Al-Khayarin M, Zirie M et al (2005) Bone density by dual energy X- ray absorptiometry in Qatari women. Maturitas 52:319-327

21. Sowers M, Crutchfield M, Bandekar R et al (1988) Bone mineral density and its changes in pre- and perimenopausal white women: the Michigan bone health study. J Bone Miner Res 13:1134-1140

22. Gallagher JC, Goldgar D, May A (1987) Total bone calcium in normal women: effect of age and menopause status. J Bone Miner Res 2:491-496

23. Arlot ME, Sornay-Rendu E, Garnero P et al (1997) Apparent preand postmenopausal bone loss evaluation by DXA at different skeletal sites in women: the OFELY Cohort. J Bone Miner Res 12:683-690

24. Newton-John HF, Morgan DB (1970) The loss of bone with age, osteoporosis and fracture. Clin Orthop 71:229-252

25. Mazess RP (1982) Ongoing bone loss. Clin Orthop 162:239-252

26. Mazess RB, Barden HS (1990) Interrelationships among bone densitometry sites in normal young women. Bone Miner 11:347356

27. Harris S, Dallal GE, Dawson-Hughes B (1992) Influence of body weight on rates of change in bone density of the spine, hip and radius in post menopausal women. Calif Tissue Int 50:19-23 